\title{
REPRESENTAÇÕES SOBRE CLIMA CRIATIVO: UMA PERSPECTIVA DE ALUNOS E DE PROFESSORES DO ENSINO BÁSICO EM ESCOLAS PÚBLICAS E PRIVADAS DE PORTUGAL
}

REPRESENTATIONS OF CREATIVE ENVIRONMENT: A PERSPECTIVE OF PRIMARY EDUCATION FOR PUPILS AND TEACHERS IN PORTUGUESE PUBLIC AND PRIVATE SCHOOLS

REPRESENTACIONES SOBRE CLIMA CREATIVO: UNA PERSPECTIVA DE ALUMNOS Y PROFESORES DE EDUCACIÓN PRIMARIA EN ESCUELAS PÚBLICAS Y PRIVADAS DE PORTUGAL

\section{Carla Dias* \\ Maria de Fátima Morais ${ }^{* *}$ \\ Ana Braga ${ }^{* * *}$}

\begin{abstract}
RESUMO
A criatividade é assumida como conceito relevante no contexto educativo. Este estudo analisou diferenças nas representações em professores de escolas públicas e privadas sobre condições favoráveis e desfavoráveis à criatividade no seu ambiente de trabalho, assim como nas representações de clima criativo em sala de aula pelos alunos desses tipos de escola. Participaram 202 alunos portugueses dos $3^{\circ}$ e $4^{\circ}$ anos do ensino básico e 72 professores. Os dados dos alunos foram recolhidos por meio da Escala sobre o Clima para a Criatividade em Sala de Aula e usou-se, para os professores, o Questionário Indicadores de Clima para a Criatividade no Ambiente de Trabalho. Os resultados revelam, para os alunos, diferenças significativas em alguns fatores, apresentando o ensino público valores superiores. Em relação aos professores, emergiram diferenças significativas em dois fatores, havendo superioridade do ensino privado nas condições favoráveis à criatividade e do ensino público nos bloqueios a esta.
\end{abstract}

Palavras-chave: Clima criativo. Aluno. Professor. Representações. Escolas públicas e privadas.

\section{ABSTRACT}

Creativity is assumed as a relevant concept in education. This study analyses differences in the representations of favorable and unfavorable conditions for creativity in the workplace by teachers from Portuguese public and private schools, and differences in representations of creative climate

\footnotetext{
Texto recebido em 12 de maio de 2014 e aprovado para publicação em 19 de maio de 2015.

Mestra em Estudos da Criança pelo Instituto de Educação da Universidade do Minho, Portugal. E-mail: carla.alexandra.ferreira. dias@gmail.com.

** Doutora em Psicologia da Educação pela Universidade do Minho, Portugal. E-mail: famorais@ie.uminho.pt.

"** Doutora em Engenharia de Produção e Sistemas pela Universidade do Minho. E-mail: acb@dps.uminho.pt.
} 
in the classroom of the 3rd and 4th grades of basic school, as well as 72 teachers. Data was collected through Scale Environment for Creativity in the Classroom in the case of students; in the case of teachers, we utilized the Questionnaire Indicators of Climate for Creativity in the Workplace. For the students, results show significant differences in several dimensions, presenting public schools higher values. In the case of teachers, emerged significant differences considering favorable conditions for creativity (higher values from private schools) and obstructions to creativity (higher values from public schools).

Keywords: Creative climate. Student. Teacher. Representations. Public and private schools.

\section{RESUMEN}

La creatividad es asumida como un concepto relevante en el contexto educativo. Este estudio examinó diferencias en las representaciones en profesores de escuelas públicas y privadas sobre condiciones favorables y desfavorables a la creatividad en su ambiente de trabajo, así como en las representaciones de clima creativo en el aula por los alumnos de esos tipos de escuela. Participaron 202 alumnos portugueses del $3^{\circ}$ y $4^{\circ}$ año de enseñanza primaria y 72 profesores. Los datos de los estudiantes fueron recogidos a través de la Escala sobre el Clima de Creatividad en el Aula y se utilizó para los profesores el Cuestionario de Indicadores del Clima para la Creatividad en el Ambiente de Trabajo. Los resultados muestran, para los alumnos, diferencias significativas en algunos factores, presentando la enseñanza pública valores más altos. En los profesores, surgieron diferencias significativas en los dos factores, habiendo superioridad de la enseñanza privada en las condiciones favorables a la creatividad y de la enseñanza pública en los bloqueos a ésta.

Palabras clave: Clima creativo. Estudiante. Maestro. Representaciones. Escuelas públicas y privadas.

\section{INTRODUÇÃO}

$\mathrm{D}$ esde sempre, o conceito de criatividade se constituiu como complexo e difícil de definir (Starko, 2010). Contudo, cada vez mais, a criatividade assume um papel de extrema importância em todos os domínios da sociedade. Como nos dizem Csikszentmihalyi (2006) ou Shaheen (2010), a criatividade como capacidade de resolver inovadoramente problemas é fundamental à sobrevivência quer social, quer do indivíduo. Atualmente, a criatividade é reconhecida como requisito urgente, transdisciplinar e transcultural para a gestão do século que se inicia (Adams, 2006; Kaufman, \& Sternberg, 2006). 
Assumindo a criatividade caráter de urgência na sociedade atual, é impensável não considerar tal importância na educação. A formação de competências criativas é considerada uma das chaves do desenvolvimento e do progresso nas escolas, reforçando a qualidade do ensino, o desenvolvimento pessoal dos alunos e o bem-estar da comunidade educativa e da sociedade (Csikszentmihalyi, 2005a; Craft, 2005). Um ensino criativo tem então sido reclamado em sala de aula (Craft, Jeffrey \& Leibling, 2007). Também o ambiente que rodeia os docentes e lhes facilita ou dificulta iniciativas de promoção de criatividade nas escolas emerge como fundamental (Alencar \& Fleith, 2008; Bruno-Faria, 2010).

As representações de criatividade, quer de professores, quer de alunos, importam na investigação sobre o conceito, já que modelam comportamentos (Moscovici, 2003) e há concepções frequentemente errôneas com impacto no quotidiano educativo (Fryer, 1996; MacLaren, 2012). Criatividade e suas representações são influenciadas também por fatores ambientais (Csikszentmihalyi, 2005b; Sternberg, \& Lubart, 1995). Pode-se, nesse âmbito, considerar a dicotomia privado/público das instituições escolares como algo agregador de diferenças psicossociais que podem fazer diferença no apelo à criatividade, podendo ainda essas diferenças serem traduzidas pelas representações dos principais agentes que as frequentam: professores e alunos (Alencar \& Fleith, 2008; Eason, Giannangelo, \& Franceschini, 2009).

Este trabalho procura então analisar representações de clima criativo em alunos e professores portugueses do $1^{\mathrm{o}}$ ciclo do ensino básico inseridos em escolas públicas e privadas.

\section{UM CLIMA CRIATIVO NO CONTEXTO ESCOLAR}

A investigação sobre criatividade tem-se debruçado bastante sobre o clima de sala de aula (Fleith, 2002; Sanchez, Martinez, \& Garcia, 2003). O que entender então por clima criativo em sala de aula? Vários autores apontam uma multiplicidade de características, havendo, porém, consenso entre eles. Por exemplo, Romo (2012) destaca um ambiente que permita ao aluno correr riscos e que associe o jogo à aprendizagem; destaca um ensino que enfatize analogias e um conhecimento interdisciplinar, assim como autoeficácia criativa sentida por alunos e professores. Também Sanchez et al. (2003) reforçam a necessidade de um ambiente no qual exista compreensão, receptividade, valorização de ideias, criando-se situações com alguma ambiguidade e promotoras de desafio cognitivo. Por sua vez, Fleith (2002) aponta as seguintes condições: proteger o trabalho criativo do aluno da crítica destrutiva; desenvolver nos alunos o pensamento de possibilidades e de exploração de consequências; incentivar nos alunos sugestôes 
de mudanças, reflexões sobre o que gostariam de conhecer e a não se deixarem vencer pelo contexto, mas a fazerem uso de seus recursos criativos para contornar obstáculos; envolver os alunos na escolha e na solução de problemas a investigar. Sternberg (2003) destaca o tempo para o pensamento criativo, a recompensa de ideias e produtos criativos, o encorajamento de riscos e de aceitação do erro como parte da aprendizagem, a imaginação de diferentes pontos de vista, o questionamento de pressupostos, a formulação de problemas e de hipóteses e a promoção de autonomia nos alunos

$\mathrm{Na}$ promoção da criatividade, o professor tem um papel crucial (Romo \& Alfonso, 2003). Por conseguinte, vários autores (Alencar \& Fleith, 2008; Sternberg, 2003) apontam um perfil de professor criativo. Este deve estar aberto a novas experiências, mostrando ousadia, curiosidade e confiança em si próprio, além de ser apaixonado pelo que faz e adotar uma postura de facilitador da aprendizagem. Dá ao aluno oportunidade de escolha, ajuda-o a lidar com o erro, apresenta indivíduos criativos como modelos, oferece diversidade de materiais e de estratégias. Os pontos fortes do aluno são por ele ressaltados, cultiva-se sentido de humor e é encorajada a autonomia do aluno. Esses autores referem ainda a importância de o docente não se deixar vencer pelas limitações do contexto, de ter expectativas positivas em relação aos alunos e de promover oportunidades para que estes se consciencializem do seu potencial criativo

Apesar do incentivo da pesquisa à prática de um ensino criativo, professores e alunos apontam barreiras ao desenvolvimento da criatividade na escola. Tem-se salientado um clima de sala de aula que não seja autoritário e estandardizado, em que o aluno não se sente valorizado e útil, mas sim em constante avaliação; não deve ser um ambiente que enfatiza a recompensa em detrimento da motivação intrínseca, havendo ainda competição em excesso, insistência na procura da resposta única e correta ou indisponibilidade face a respostas inesperadas (Alencar \& Fleith, 2008; Beghetto, 2010).

Outro tipo de barreiras à expressão criativa são as condições físicas e institucionais onde os docentes trabalham. Como referem Alencar e Fleith (2008), "Percebendo-se [...] desprovidos de maiores recursos para uma atuação mais eficaz, dificilmente os docentes sentir-se-ão realizados no plano pessoal e profissional" (p. 64). O professor necessita de um ambiente onde várias condições se conjuguem para a promoção de um clima criativo. Para isso acontecer, é necessário ter em conta fatores como a estrutura e o suporte organizacional da instituição, a gestão e o suporte específico da direção, a comunicação entre docentes e entre a direção e estes, a liberdade de ação e autonomia do docente possibilitadas pela instituição, os recursos materiais e humanos nela existentes, assim como a remuneração, benefícios sociais ou o acesso a formação 
ou informação. Esses aspetos contribuem para a inibição ou a estimulação da criatividade no ambiente quotidiano de trabalho (Bruno-Faria, 2010; Karnal, 2003; Mariani \& Alencar, 2005).

\section{REPRESENTAÇÕES SOBRE CLIMA CRIATIVO EM ALUNOS E DOCENTES}

Não se pode pensar no desenvolvimento de um clima criativo em sala de aula sem ter em conta as representações que docentes e alunos têm acerca deste. Isso porque as representaçôes moldam atitudes e comportamentos (Moscovici, 2003). O próprio conceito de criatividade nem sempre é entendido claramente, havendo vários mitos a ele associados e que podem interferir no investimento em competências criativas (MacLaren, 2012; Morais, 2013). Especificamente no que respeita aos docentes, investigações apontam associações erradas da criatividade a uma inspiração súbita e inexplicável, a capacidades meramente intelectuais, ao contexto artístico ou à indisciplina (Fryer, 1996; Morais \& Azevedo, 2008). Contudo, diante da relevância da criatividade, da possibilidade de nela intervir e diante dos conceitos de docente e de aluno criativos, surgem também, por parte dos professores, representações que correspondem ao que é afirmado pela investigação (Fryer, 1996; Morais \& Azevedo, 2008).

Quanto às representações dos docentes sobre as condições físicas e institucionais do ambiente de trabalho e a sua relação com criatividade, são referidos obstáculos em investigações brasileiras (Alencar \& Fleith, 2008; Mariani \& Alencar, 2005). É mencionada a sobrecarga de trabalho, como a quantidade de aulas, o exercício de várias funções ou o excesso de burocracia. Também a falta de recursos materiais para atividades inovadoras é referida. Há ainda críticas quanto ao distanciamento entre o discurso teórico e político e a prática escolar, à estrutura organizacional da escola, assim como a lacunas na formação profissional, insuficiente colaboração dos colegas ou falta de tempo. Foram ainda referidas a ausência de orientação sobre metodologias de ensino, qualidade e obrigatoriedade de livros adotados e a falta de professores para áreas específicas. Não se conhecendo estudos em Portugal (onde o estudo empírico narrado neste artigo foi conduzido) sobre este tipo de representaçôes, pensa-se, porém, que o panorama não será muito diferente no que respeita às preocupações dos docentes anteriormente mencionadas (Alencar \& Fleith, 2008; Mariani \& Alencar, 2005).

Conhecer as representações dos alunos é também relevante quando há a preocupação com o investimento em criatividade no contexto escolar (Azevedo, 2007; Runco, Johnson, \& Baer, 1993). Alguns estudos sobre essas 
representações mostram uma avaliação positiva da influência do contexto escolar no desenvolvimento da criatividade (Fleith \& Alencar, 2006; Cavalcanti, 2009), mas outros trabalhos (Alencar \& Fleith, 2004; Fraser, 1984) sugerem que nem sempre o clima de sala de aula preferido pelos alunos coincide com o que eles vivenciam. Estudos de Fleith $(2002,2006)$, por sua vez, revelam que a autonomia do aluno foi percebida como uma caraterística pouco incentivada pelos professores.

Conhecer as representaçóes dos professores e dos alunos acerca do clima criativo pode então ajudar a perceber necessidades e a desenhar consequentes intervençôes. Pode-se captar ideias míticas e mesmo prejudiciais para a educação em relação à criatividade, tal como identificar crenças potencialmente positivas e a reforçar (Monteiro, 2009; Morais \& Azevedo, 2008).

\section{REPRESENTAÇÕES DE CRIATIVIDADE NO ENSINO PRIVADO/PÚBLICO}

Por último, surge a preocupação sobre a possível influência do tipo de contexto escolar, particularmente público ou privado, nas representações de clima criativo, apesar de existirem poucos estudos sobre o tema. Alencar e Fleith (2008) estudaram as representações de professores sobre as barreiras ao desenvolvimento da criatividade em escolas de contextos público e privado. Notaram diferenças significativas entre professores dos dois contextos, emergindo mais barreiras na escola pública. As barreiras mais apontadas nesse estudo foram o elevado número de alunos por sala, os alunos com dificuldade de aprendizagem, o baixo reconhecimento do trabalho do professor, a extensão do programa a lecionar, alunos indisciplinados, o desinteresse dos alunos, a escassez de material didático, poucas oportunidades para trocar ideias sobre estratégias de ensino, a falta de apoio institucional a projetos inovadores, a qualidade dos livros adotados na escola. As barreiras menos apontadas foram a falta de oportunidade para atividades fora da sala de aula, a falta de orientação pedagógica da escola em relação ao desenvolvimento da criatividade do aluno, o desconhecimento de práticas e de textos para tal desenvolvimento, a insegurança para testar novas práticas docentes, a falta de autonomia nas atividades e a falta de entusiasmo pela profissão.

Ora, apenas em três dos itens anteriores não houve diferenças significativas entre professores de escolas públicas e privadas: presença de alunos indisciplinados, poucas oportunidades para trocar ideias sobre estratégias de ensino, falta de autonomia. Nos itens reveladores de diferenças significativas, a única barreira mais apontada por professores de escolas particulares (46,3\%) em relação aos 
das públicas $(30,7 \%)$ foi a extensão do programa a lecionar; em todos os outros itens, surgiram maiores dificuldades nas escolas públicas.

Também Fleith (2007) revelou que os alunos de escolas particulares apresentavam melhor desempenho criativo se comparados aos de escolas públicas. No mesmo sentido, Karwowski, Lebuda e Wisniewska (2008) verificaram que os alunos de escolas privadas são caracterizados por maior nível de habilidades criativas e por estilos de inovação superiores em comparação aos alunos de escolas públicas. Num contexto cultural diferente como a Índia, essa superioridade de realização criativa em escolas privadas também se verificava (Gupta, 1978; Sarsani, 1989) e verifica atualmente (Tasaduq \& Azim, 2012).

Estudos como os de Fleith e Alencar (2006), Fleith (2006) ou Castro (2007) mostraram ainda que os alunos de escolas particulares apresentavam uma representação mais positiva acerca do clima de sala de aula como sendo favorável à criatividade. Os alunos dessas escolas consideraram-se também mais criativos e percebiam o clima de sala de aula como mais favorável à sua autonomia.

Em relação aos docentes, Eason et al. (2009) verificaram que os professores de escolas privadas avaliavam os seus alunos como sendo mais criativos e percebiamse como sendo mais criativos também. Estes docentes também valorizavam mais a criatividade do que os professores das escolas públicas.

Apesar de a literatura ser escassa a respeito da criatividade nesses dois contextos escolares, há então diferenças na realização criativa, nas representações sobre esta e nas condições da sua promoção em sala de aula. Parece ser assim um tópico de investigação a investir, nomeadamente em Portugal, onde há desconhecimento sobre a questão.

\section{MÉTODO}

\subsection{Objetivos e hipóteses}

Pretendeu-se analisar representaçôes de alunos e professores do $1^{\circ}$ ciclo do ensino básico, inseridos em escolas públicas e privadas, sobre clima criativo: em sala de aula, no caso dos alunos; no ambiente de trabalho, no caso dos professores. Presume-se que, em ambos os casos, existam diferenças estatisticamente significativas conforme a tipologia de escolas (públicas/privadas).

\subsection{Participantes}

Participaram no estudo 202 alunos dos $3^{\circ}$ e $4^{\circ}$ anos do ensino básico, frequentando 107 o ensino público (4 escolas) e 95 o ensino privado (4 escolas) 
de um mesmo distrito português (Braga). Tinham idades compreendidas entre 8 e 12 anos (média de 8,8 anos), sendo 106 do gênero feminino e 96 do masculino. As escolas públicas estavam inseridas em contexto socioeconômico baixo (bairros sociais, incluindo alunos de etnia cigana) e as privadas, estas associadas a contexto socioeconômico elevado de seus alunos (colégios requerendo pagamento de mensalidades elevadas e não obtendo subsídios públicos). Os professores pertenciam a escolas públicas e privadas com as mesmas características referidas para os alunos. Participaram 72 professores, lecionando 37 no ensino público e 35 no ensino privado. Desses professores, 59 são do gênero feminino e 13 do gênero masculino, tendo idades compreendidas entre 25 e 60 anos (média de 36 anos).

\subsection{Instrumentos}

Aos alunos foi aplicada a "Escala sobre o Clima para a Criatividade em Sala de Aula”, adaptada à população portuguesa (Dias, 2014), baseada na versão de Fleith e Alencar (2005). A escala avalia fatores percebidos como estimuladores e como inibidores à expressão da criatividade no contexto escolar. O instrumento tem 22 itens, com respostas apresentadas em escala Likert de 5 pontos (entre "nunca" e "sempre"), estando organizados os itens em 4 fatores: suporte do professor à expressão de ideias do aluno (exemplo: "A professora dá atenção às minhas ideias"), autopercepção do aluno quanto à criatividade (exemplo: "Uso a minha imaginação"), interesse do aluno pela aprendizagem na escola (exemplo: "Aprendo coisas de que realmente gosto"), autonomia do aluno na escola (exemplo: "Posso escolher o que quero fazer"). A escala explica 51,7\% da variância dos resultados e os coeficientes alfa de Cronbach oscilam entre $.52 \mathrm{e}$ .83. A aplicação da escala não tem duração estipulada.

Aos professores foi aplicado o questionário "Indicadores de Condições para a Criatividade no Ambiente de Trabalho", adaptado ao contexto português e educativo (Dias, 2014). Trata-se de um inventário com 55 itens, baseado em versões brasileiras (Bruno-Faria \& Alencar, 1998; Bruno-Faria \& Veiga, 2015) e cujas respostas são dada numa escala Likert de 5 pontos (entre "discordo plenamente" e "concordo plenamente"). Os itens estão organizados em três fatores, dois dos quais avaliam estímulos à criatividade no ambiente de trabalho (liberdade de ação, desafios e clima favorável entre colegas. Exemplo: “Tenho liberdade para decidir como realizar as tarefas"; disponibilidade e adequação de recursos materiais e organizacionais. Exemplo: "A escola oferece acesso a uma variedade de fontes de informação") e correspondendo o outro a obstáculos em relação a esse objetivo (bloqueios à criatividade. Exemplo: "A rigidez das regras 
na escola dificulta o aparecimento de novas ideias"). A variância de resultados explicada é de $44.7 \%$ e os alfas de Cronbach oscilaram entre .89 e .94. A aplicação do questionário não tem duração estipulada.

\subsection{Procedimentos}

Em relação à participação das crianças, foram informados os diretores das escolas sobre o objetivo do estudo, os instrumentos a aplicar e dada a garantia de anonimato dos dados. Foi solicitado à $\mathrm{DGIC}^{1}$ autorização para aplicação dos questionários e ainda uma autorização escrita aos encarregados de educação. A aplicação da escala decorreu em sala de aula, durante cerca de 30 minutos. Foi explicado aos alunos o objetivo da atividade, assim como referida a sua relevância, garantindo sempre o anonimato dos questionários e o seu caráter não avaliativo em nível escolar. Os professores foram contatados individualmente ou por meio das direçôes das escolas. Após conhecerem os objetivos do estudo, o preenchimento do questionário foi efetuado fora do contexto de sala de aula, individualmente e sem controle de tempo. Foi garantido aos professores o anonimato de todos os dados. Este estudo foi conduzido em 2013. Para o tratamento de todos os dados obtidos, recorreu-se à análise fatorial exploratória, por meio do programa SPSS, versão 22.0.

\section{RESULTADOS E DISCUSSÃO}

Inicialmente apresentam-se os dados descritivos da aplicação dos instrumentos aos participantes. $\mathrm{Na}$ tabela 1 , são indicados os valores de $\mathrm{N}$, das médias $(\mathrm{M})$, desvios-padrão (DP) e os valores mínimos e máximos para cada parâmetro da "Escala Clima para a Criatividade em Sala de Aula" e do "Questionário Indicadores de Condições para a Criatividade no Ambiente de Trabalho". Nas tabelas 2 e 3, os dados são discriminados pelas escolas de ensino público/privado, para os alunos e para os professores, respectivamente.

Tabela 1. Análise dos resultados na amostra global

\begin{tabular}{|c|c|c|c|c|c|}
\hline Parâmetros & $\mathbf{N}$ & $\mathbf{M}$ & DP & Mínimo & Máximo \\
\hline $\begin{array}{l}\text { Suporte do professor à expressão de ideias } \\
\text { do aluno }\end{array}$ & 202 & 4.13 & .62 & 2 & 5 \\
\hline Interesse do aluno pela aprendizagem & 202 & 4.41 & .53 & 1 & 5 \\
\hline $\begin{array}{l}\text { Autopercepção do aluno quanto à } \\
\text { criatividade }\end{array}$ & 202 & 3.99 & .81 & 1 & 5 \\
\hline Autonomia do aluno & 202 & 3.19 & .88 & 1 & 5 \\
\hline
\end{tabular}

Fonte: elaborado pelas autoras.

1 Direção-Geral de Educação - Serviço de Monitorização de Inquéritos em Meio Escolar. 
Tomando a tabela 1, na "Escala Clima para a Criatividade em Sala de Aula", verificou-se que as médias oscilam entre 3.19 e 4.41, e os desvios-padrão, entre .53 e .88 , não havendo grande dispersão de valores e sendo a amplitude de respostas para os parâmetros elevada (entre $1 \mathrm{e} 5 \mathrm{em}$ quase todos). Quanto ao "Questionário Indicadores de Condições para a Criatividade no Ambiente de Trabalho", verifica-se que as médias oscilam entre 2.57 e 4.46, e os desvios-padrão, entre .52 e .78. A amplitude de respostas emerge como razoável, notando-se menor amplitude em liberdade de ação, clima favorável entre colegas e desafios.

Considerando os subgrupos de alunos das escolas de ensino privado/ensino público avaliadas (tabela 2), as médias oscilam entre 3.38 e 4.55 (público) e entre 2.98 e 4.25 (privado), e os desvios-padrão, entre .42 e .94 (público) e entre .61 e .86 (privado). Porém, se tomarmos a amplitude de respostas, nas escolas de ensino público da amostra, apenas em autonomia do aluno existem todas as pontuaçóes, verificando-se boa amplitude do conjunto dos parâmetros nas de ensino privado.

Tabela 2. Análise dos resultados dos alunos por contexto de ensino

\begin{tabular}{|c|c|c|c|c|c|c|}
\hline Parâmetros & Escola & N & M & DP & Mínimo & Máximo \\
\hline $\begin{array}{c}\text { Suporte do professor à expressão } \\
\text { de ideias do aluno }\end{array}$ & Público & 107 & 4.34 & .55 & 3 & 5 \\
\cline { 2 - 7 } & Privado & 95 & 3.90 & .61 & 2 & 5 \\
\hline \multirow{2}{*}{$\begin{array}{c}\text { Interesse do aluno pela } \\
\text { aprendizagem }\end{array}$} & Público & 107 & 4.55 & .42 & 3 & 5 \\
\cline { 2 - 7 } & Privado & 95 & 4.25 & .61 & 1 & 5 \\
\hline \multirow{2}{*}{$\begin{array}{c}\text { Autopercepção do aluno quanto } \\
\text { à criatividade }\end{array}$} & Público & 107 & 4.02 & .76 & 2 & 5 \\
\cline { 2 - 7 } & Privado & 95 & 3.97 & .86 & 1 & 5 \\
\hline \multirow{2}{*}{\begin{tabular}{c} 
Autonomia do aluno \\
\cline { 2 - 7 }
\end{tabular}} & Público & 107 & 3.38 & .94 & 1 & 5 \\
\cline { 2 - 7 } & Privado & 95 & 2.98 & .75 & 1 & 5 \\
\hline
\end{tabular}

Fonte: elaborado pelas autoras.

No que diz respeito aos professores e suas representaçôes sobre condições favoráveis e desfavoráveis à criatividade no ambiente de trabalho (cf. tabela 3), as médias oscilam entre 2.1 e 4.4, variando os desvios-padrão entre .50 e .55 . 
A amplitude de respostas em liberdade de ação, desafio e clima favorável entre colegas é restrita a valores entre 3 e 5 para ambos os contextos de ensino, assim como as escolas de ensino privado em disponibilidade e adequação de recursos materiais e organizacionais.

Tabela 3. Análise dos resultados dos professores por contexto de ensino

\begin{tabular}{|c|c|c|c|c|c|c|}
\hline Parâmetros & Contexto & N & M & DP & Mínimo & Máximo \\
\hline \multirow{2}{*}{$\begin{array}{c}\text { Liberdade de ação, desafios e } \\
\text { clima favorável entre colegas }\end{array}$} & Público & 37 & 4,41 & .52 & 3 & 5 \\
\cline { 2 - 7 } & Privado & 35 & 4.52 & .52 & 3 & 5 \\
\hline $\begin{array}{c}\text { Disponibilidade e adequação } \\
\text { de recursos materiais e } \\
\text { organizacionais }\end{array}$ & Público & 37 & 3.51 & .75 & 2 & 5 \\
\cline { 2 - 7 } & Privado & 35 & 4.33 & .56 & 3 & 5 \\
\hline $\begin{array}{c}\text { organion à criatividade } \\
\text { Bloqueios }\end{array}$ & Público & 37 & 2.95 & .54 & 2 & 4 \\
\cline { 2 - 7 } & Privado & 35 & 2.17 & .50 & 1 & 3 \\
\hline
\end{tabular}

Fonte: elaborado pelas autoras.

Para o cálculo das diferenças de médias para alunos e professores, foi testado se as distribuições dos parâmetros se aproximavam significativamente da distribuição normal. Como isso aconteceu, usou-se o teste paramétrico $t$-Student para duas amostras independentes. Da análise das representações sobre clima criativo em sala de aula entre alunos das escolas públicas e privadas avaliadas, emergiram diferenças estatisticamente significativas em suporte do professor à expressão de ideias do aluno $(\mathrm{t}=-3.670 ; \mathrm{gl}=200 ; \mathrm{p}<.05)$, interesse do aluno pela aprendizagem $(\mathrm{t}=-3.490 ; \mathrm{gl}=153.957 ; \mathrm{p}<.05)$ e autonomia do aluno $(\mathrm{t}=-$ 3,673; $\mathrm{gl}=198.383 ; \mathrm{p}<.05)$, havendo valores superiores nos alunos das escolas do ensino público. Embora a literatura a esse nível seja escassa, constata-se que esses dados não vão ao encontro de outros obtidos com a mesma escala em amostras brasileiras de semelhante faixa etária de (Alencar \& Fleith, 2006; Castro, 2007), mostrando estes últimos a superioridade do ensino privado.

Podem obviamente estar aqui em causa diferenças culturais (diferentes áreas geográficas, sistemas de ensino, valores implicitamente reforçados) a condicionar percepções (Runco \& Albert, 2005), não se tendo mais estudos em contexto português para comparar. Porém, independentemente de comparações internacionais, esse resultado poderá indiciar que o ensino público português, 
nesse ciclo de ensino, transmite uma aposta maior no clima criativo em sala de aula do que o ensino privado, sendo essa possibilidade coerente com dados de outros estudos em outras faixas etárias (David, 2008). Neste último, mostrouse que são os alunos do ensino público, em relação ao privado, a terem melhor desempenho no ensino superior, mesmo que os segundos possam exibir maiores resultados de acesso; parece, assim, que o ensino público prepara melhor para a vida, independentemente da preparação mais pontual para exames. Esse resultado pode ser então um dado positivo que vem desmistificar eventuais representaçóes portuguesas do ensino privado como sendo de maior qualidade no ensino-aprendizagem, se nesta se incluir a promoção de um clima criativo em sala de aula. Mais à frente, este comentário explicativo será retomado em cruzamento com outros resultados.

Não se pode esquecer, porém, que a avaliação realizada incide em representações; então, uma melhor percepção de clima criativo pelos alunos das escolas públicas poderá também traduzir mais fortes lacunas destes nas dimensões avaliadas (incentivo à expressão, interesse pelo aluno, tarefas de aprendizagem, apelo à autonomia...) nos seus outros contextos de vida, nomeadamente sociofamiliares, e assim estarem a sobrevalorizar tais dimensões no contexto escolar em relação aos colegas do ensino privado. Note-se, nesta última hipótese, que as escolas públicas em causa estão inseridas em bairros sociais com fortes carências sociais e econômicas, as quais podem repercutir-se em estilos parentais e relacionais em geral menos propícios ao incentivo da autorrealização e da criatividade.

Independentemente das diferenças obtidas, recorda-se que os parâmetros suporte do professor à expressão de ideias do aluno, interesse do aluno pela aprendizagem e autopercepção do aluno face à criatividade foram positivamente avaliados nas escolas dos dois contextos de ensino (tabela 2), indicando que ambos os tipos de alunos têm uma visão positiva de seu potencial criador, assim como das tarefas realizadas em sala de aula, o que sublinha uma perspectiva otimista se pensarmos que representações influenciam práticas (Moscovici, 2003). Também esses dados vão ao encontro de estudos sobre representações de alunos que indicam influência positiva do contexto escolar no desenvolvimento da criatividade (Cavalcanti, 2009; Fleith \& Alencar, 2006). Como nos dizem Alencar \& Fleith (2006), fatores como as práticas educacionais, a relação entre professor e aluno e as oportunidades de aprendizagem oferecidas têm forte influência no modo como os alunos se comportam, tendo ainda o professor um papel central na sala de aula, visto que as suas práticas e atitudes levam os alunos a desenvolverem capacidades criativas com prazer, manifestando gosto pela aprendizagem e expressando autonomia nas suas escolhas. Ora, isso estará subjacente nas duas possibilidades explicativas para as diferenças encontradas. 
Em ambos os tipos de escola em causa neste estudo, a autonomia do aluno foi o fator menos positivamente avaliado (tabela 2), não havendo diferença significativa entre eles. Esse resultado corrobora estudos como os de Cavalcanti (2009) ou de Fleith \& Alencar (2006). Gonçalves, Fleith e Libório (2011) referem ainda a iniciativa e a autonomia nos alunos como sendo deficitariamente estimulados em sala de aula.

Por seu lado, na análise das representações sobre o ambiente criativo no quotidiano de trabalho entre os professores das escolas públicas e privadas do estudo, emergiram diferenças estatisticamente significativas em disponibilidade e adequação de recursos materiais e organizacionais $(\mathrm{t}=5,258 ; \mathrm{gl}=70 ; \mathrm{p}<$ $.05)$, havendo superioridade dos professores das escolas de ensino privado; e em bloqueios à criatividade $(\mathrm{t}=-6,362 ; \mathrm{gl}=70 ; \mathrm{p}<.05)$, com superioridade dos professores das escolas de ensino público.

Se forem recordadas as médias obtidas nos parâmetros deste questionário (tabela 3), verifica-se que os professores de ambos os contextos de ensino afirmam terem autonomia na gestão do seu trabalho, serem desafiados com atividades estimulantes e usufruírem de um bom clima de trabalho entre colegas (liberdade de ação, desafios e clima favorável entre colegas). Todavia, voltando às diferenças das médias, os professores das escolas de ensino público avaliadas constatam mais condições desfavoráveis no seu ambiente de trabalho para o desenvolvimento da criatividade, nomeadamente quanto a recursos materiais e organizacionais, estando estes últimos muito ligados ao incentivo de inovação por parte de superiores (disponibilidade e adequação de recursos materiais e organizacionais) e quanto a obstáculos de tempo e de excesso de tarefas, assim como de falta de flexibilidade nas regras da escola e de comunicação com os superiores (bloqueios à criatividade).

Havendo alguns estudos que demonstram representações dos docentes sobre obstáculos à criatividade no seu ambiente de trabalho (Alencar \& Fleith, 2008; Mariani \& Alencar, 2005), se forem tomados especificamente os contextos de ensino privado/público, os dados deste estudo vão ao encontro de resultados obtidos por Alencar e Fleith (2008), tendo essas autoras constatado que os professores do ensino público percebem no seu ambiente de trabalho mais barreiras ao desenvolvimento da criatividade, nomeadamente no que diz respeito a recursos materiais, incentivo a inovar e falta de apoio institucional.

A esses resultados não será talvez distante a situação econômica atual que o país atravessa, assim como uma desvalorização do professor e da escola pública nos últimos anos, e não somente em Portugal. Essas situações são traduzidas, por exemplo, pela diminuição de benefícios na carreira docente, por excesso 
de burocracia, de normas, de carga horária e de alunos. Esses são aspetos que os professores podem conceber como limitadores do desenvolvimento da criatividade no quotidiano educativo (Azevedo, 2007; David, 2008; Mariani \& Alencar, 2005).

Sendo as hipóteses dessa investigação verificadas, consideremos agora o cruzamento de resultados provindos dos alunos e dos docentes de ambos os contextos de ensino. Docentes das escolas de ensino público aqui avaliadas sentem tais escolas como detendo mais dificuldades concretas quanto ao desenvolvimento da criatividade (na comunicação com superiores, na formulação das regras, na burocracia, no tempo e quantidade de tarefas, por exemplo), o que é suportado por outras investigações em Portugal (David, 2008) e noutros países (Alencar \& Fleith, 2008). Mesmo se tratando de amostras independentes (professores e alunos), olhando as percepçóes positivas dos alunos do ensino público, não se resiste a interrogar se barreiras mais percebidas pelos docentes desse tipo de ensino podem não limitar um clima em sala de aula tido pelos alunos como criativo. Os docentes do ensino público, diante das dificuldades, serão suficientemente resilientes, tomando mesmo as dificuldades percebidas como necessidades a ultrapassar no quotidiano? Também não se pode esquecer que o ensino privado, pelas contingências econômicas que acarreta aos encarregados de educação, pode pautar-se por maior exigência acadêmica, a qual passa ainda essencialmente pela aplicação de um pensamento convergente e pela memorização (Lubart, 2007). Maior controle comportamental, maior apelo à normatividade e menor permissividade da divergência e da crítica podem ainda marcar mais o ensino privado, já que o público se pauta pela diversidade, cada vez maior, e pela integração de diferenças numa massificação de alunos crescente também (Frazão, 2011). Tais condiçõos diferenciadas em ambos os tipos de ensino podem fazer com que as competências criativas sejam mais estimuladas na sala de aula do ensino público, independentemente das dificuldades de seus docentes.

Parece relevante pensar que, se as condições dos docentes do ensino público fossem melhores, havendo menores barreiras, poderia verificar-se maior rentabilização das possibilidades de um clima criativo em sala de aula. Formação sistemática e intencional de docentes, mas também de órgãos responsáveis por escolas e mesmo por políticas educativas, envolvendo o nível pessoal, mas também o clima institucional, parece surgir como muito pertinente para coincidirem condições de promoção da criatividade em sala de aula (Park, Lee, Oliver, \& Cramond, 2006). A rentabilização referida em relação aos docentes do ensino público poderá igualmente ajudar docentes e alunos se a superioridade das diferenças nas representações destes últimos for explicável por carências vividas 
noutros contextos que não o escolar e, assim, sobrevalorizar a criatividade em sala de aula.

Uma intervenção sistêmica e dirigida para a rentabilização da escola não será importante apenas no ensino público, mas também no privado. Neste último contexto, e tomando a amostra deste estudo, no quotidiano de trabalho dos docentes, foram notadas menos barreiras e mais estímulos à criatividade, existindo alunos a perceberem um clima de sala de aula que poderia ser mais apelativo à criatividade. Institucionalmente, a mensagem sobre a urgência das competências criativas no mundo atual (Kaufman \& Sternberg, 2006; Starko, 2010) deveria passar também nesse contexto de ensino e não somente por ações de promoção pontuais nos docentes e nos alunos, mas atravessando os valores mais latos da cultura escolar.

\section{CONSIDERAÇÕES FINAIS}

A criatividade, como necessidade pessoal e social, é inquestionável no mundo contemporâneo (Starko, 2010), revelando-se fundamental no contexto escolar (Craft, 2005). Embora uma avaliação positiva pelos alunos sobre a influência do contexto escolar no desenvolvimento da criatividade seja mostrada (Cavalcanti, 2009), outros estudos (Alencar \& Fleith, 2004; Johnson \& Johnson, 1999) sugerem que nem sempre o clima de sala de aula desejado pelos alunos coincide com o que vivenciam. É fundamental então criar condições para um clima criativo em sala de aula (Romo, 2012). Torna-se ainda relevante conhecer as representaçóes de professores e de alunos sobre um clima criativo que os envolve, pois tais representaçóes moldam práticas potenciadoras ou inibidoras de criatividade (Morais \& Azevedo, 2008). Apesar da escassa literatura sobre esse tema quanto ao ensino privado ou público, verifica-se um predomínio de representações positivas por alunos e docentes de escolas privadas (Fleith, 2007; Karwowski et al., 2008).

Este estudo indicou que os alunos das escolas de ensino público avaliadas, em relação ao privado, percebiam o clima em sala de aula como mais criativo. Esses dados contrariam outras investigações, sobretudo conduzidas no Brasil e usando a escala aplicada neste estudo (Castro, 2007; Eason et al., 2009). Diferenças culturais podem estar aqui em causa (Runco \& Albert, 2005). Pode-se sugerir, porém, que o ensino público português pode estar a veicular para as crianças desse nível de ensino um clima de sala de aula mais favorável à criatividade do que o ensino privado, tendo essa mensagem implicações para ambos os contextos. Nos professores avaliados, evidenciaram-se mais dificuldades e menos incentivos à criatividade nos ambientes de trabalho do ensino público. Num 
cenário de escassa pesquisa, aqui já se encontra consenso com outra investigação (Alencar \& Fleith, 2008). Talvez valores diferentes na cultura institucional escolar (crescente desvalorização da escola pública, paralela à crise econômica) possam não ser alheios a essas percepções.

Em estudos futuros, sugere-se o recurso a amostras maiores e mais abrangentes do país (apesar da sua pequena dimensão), não se podendo fazer generalizações com base em amostras de conveniência, mas apenas sugerir pistas para refletir e desenvolver investigação. Também se poderia, no caso dos docentes, procurar similaridade entre gêneros, escalóes etários e tempos de serviço. Seriam ainda interessantes a análise da relação entre as representações sobre clima criativo e a realização criativa, quer em alunos, quer em professores, tomando os dois contextos de ensino, assim como a comparação entre representaçôes de clima criativo em sala de aula por alunos e docentes desses contextos e até das mesmas turmas. Estudos similares em outros anos de escolaridade, por exemplo, contrastando o $1^{\circ}$ e o $4^{\circ}$ anos, seriam também potencialmente úteis. Focando os docentes, um levantamento de caraterísticas estruturais e comunicacionais de instituiçóes escolares dos dois contextos de ensino e sua relação com a criatividade docente poderia ser relevante para perceber variáveis comuns a ambos os contextos permissoras de um corpo docente criativo.

Deste estudo surgem já potenciais reflexões para a formação de professores e para a gestão pedagógica das escolas. As escolas de ensino público avaliadas neste estudo parecem legitimar otimismo em relação à presença da criatividade percebida pelos alunos, mas também legitimar necessidades dos seus docentes, as quais sugerem investimentos não somente de formação individual, mas sobretudo tomando a cultura/comunicação institucional. Esse investimento de ordem mais alargada quanto à criatividade surge requerido também pelas escolas de ensino privado avaliadas se forem tomadas as representaçóes dos alunos. Essa análise pode ser então um passo relevante para a investigação sobre criatividade e para intervenções psicossociais quanto a competências criativas em contexto escolar. 


\section{REFERÊNCIAS}

Adams, K. (2006). The sources of innovation and creativity: a paper commissioned by the National Center on Education and the Economy for the New Commission on the Skills of the American Workforce. Washington: National Center on Education and the Economy.

Alencar, E. M. L. S. de \& Fleith, D. de S. (2004). Creativity in university courses: perceptions of professors and students. Gifted and Talented International, 19(1), 24-28.

Alencar, E. M. L. S. de \& Fleith, D. de S. (2006). Práticas pedagógicas que promovem a criatividade segundo professores do ensino fundamental (relatório de pesquisa). Brasília: Conselho Nacional de Desenvolvimento Científico e Tecnológico.

Alencar, E. M. L. S. de \& Fleith, D. de S. (2008). Barreiras à promoção da criatividade no ensino fundamental. Psicologia: Teoria e Pesquisa, 24(1), 59-66.

Azevedo. M. I. P. de (2007). Criatividade e percurso escolar: um estudo com jovens do ensino básico. (Tese de Doutorado), Universidade do Minho, Braga.

Beghetto, R. A. (2010). Creativity in the classroom. In J. C. Kaufman \& R. J. Sternberg (Eds.), Cambridge handbook of creativity. (pp. 447-463). New York: Cambridge University Press.

Bruno-Faria, M. F. (2010). Indicadores de clima para a criatividade no ambiente de trabalho. In E. M. L. S. de Alencar, M. F. Bruno-Faria \& D.de S. Fleith (Orgs.), Medidas de Criatividade: teoria e prática. (pp. 113-134). Porto Alegre: Artmed.

Bruno-Faria, M. F. \& Alencar, E. M. L. S. de (1998). Indicador de clima para criatividade: um instrumento de medida da percepção de estímulos e barreiras à criatividade no ambiente de trabalho. Revista de Administração, 33 (4), 8691.

Bruno-Faria, M. F. \& Veiga, H. M. da S. (2015). Indicadores de condições para criar no ambiente de trabalho: evidências de validação empírica de uma medida. Revista de Administração, 50(4), 492-506.

Castro, J. S. R. de (2007). Criatividade escolar: relação entre tempo de experiência docente e tipo de escola. (Dissertação de Mestrado), Universidade de Brasília, Brasília. 
Cavalcanti, M. M. P. (2009). Relação entre motivação para aprender, percepção do clima de sala de aula para criatividade e desempenho escolar de alunos do $5^{\circ}$ ano do ensino fundamental. (Dissertação de Mestrado). Universidade de Brasília, Brasília.

Craft, A. (2005). Creativity in schools: tensions and dilemmas. London: Routledge.

Craft, A., Jeffrey, B. \& Leibling, M. (2007). Creativity in education. London: Continuum.

Csikszentmihalyi, M. (2005a). Educar para uma boa sociedade. In A. Pinto, J. Conde \& M. Conde (Eds.), Ensinar e aprender no novo milénio. (pp. 53-57). Lisboa: Associação Educativa para o Desenvolvimento da Criatividade.

Csikszentmihalyi, M. (2005b). Implications of a systems perspective for the study of creativity. In R. Sternberg (Ed.), Handbook of creativity. (pp. 313335). Cambridge: Cambridge University Press.

Csikszentmihalyi, C. (2006). Developing creativity. In N. Jackson, M. Oliver, M. Shaw \& J. Wisdom (Orgs.), Developing creativity in higher education. (pp. xviii-xx). London: Routledge.

David, A. P. (2008). Competências criativas no ensino secundário: um estudo com diferentes anos de escolaridade e áreas acadêmicas. (Dissertação de Mestrado), Universidade Católica Portuguesa, Lisboa.

Dias, C. A. F. (2014). Criatividade no ensino básico: um olhar sobre as representaçôes de alunos e de professores em escolas públicas e privadas. (Dissertação de Mestrado), Universidade do Minho, Braga.

Eason, R., Giannangelo, D. M. \& Franceschini, L. A. (2009). A look at creativity in public and private schools. Thinking Skills and Creativity, 4(2), 130-137.

Fleith, D. S. (2002). Ambientes educacionais que promovem a criatividade e excelência. Sobredotação, 3, 27-39.

Fleith, D. S. (2006). Características personológicas e fatores ambientais relacionados ao desenvolvimento da criatividade no contexto educacional (relatório de pesquisa). Brasília: Conselho Nacional de Desenvolvimento Científico e Tecnológico.

Fleith, D. S. (2007). A promoção da criatividade no contexto escolar. In A. M. R. Virgolim (Org.), Talento criativo: expressão em múltiplos contextos. (pp. 145157). Brasília: Editora Universidade de Brasília. 
Fleith, D. S. \& Alencar, E. M. L. de S. (2005). Escala sobre o clima para criatividade em sala de aula. Psicologia: Teoria e Pesquisa, 21(3), 85-91.

Fleith, D. S. \& Alencar, E. M. L. de S. (2006). Percepção de alunos do ensino fundamental quanto ao clima de sala de aula para criatividade. Psicologia em Estudo, 11(3), 513-521.

Fraser, B. J. (1984). Differences between preferred and actual classroom environment as perceived by primary students and teachers. British Journal of Educational Psychology, 54(3), 336-339.

Frazão, R. M. (2011). Práticas de diversificação: diferenciação curricular no contexto das políticas educativas para o ensino básico. (Tese de Doutorado), Universidade Católica Portuguesa, Lisboa.

Fryer, M. (1996). Creative teaching and learning. London: Paul Chapman.

Gonçalves, F. C., Fleith, D. S. \& Libório, A. C. O. (2011). Criatividade em aula: percepção de alunos de dois estados brasileiros. Arquivos Brasileiros de Psicologia, 63(1), 22-30.

Gupta, A. K. (1978). Study of pupil creativity in two institutional settings. The Journal of Creative Behavior, 12(3), 218-218.

Johnson, W. L. \& Johnson, A. M. (1999). Assessing perception of school climate among Jordanian students in English-Speaking schools. Psychological Reports, 84 (2), 395-397.

Karnal, L. (2003). História na sala de aula: conceitos, práticas e propostas. São Paulo: Contexto.

Karwoswski, M., Lebuda, I. \& Wisniewska, E. (2008). Creative abilities and styles as predictors of school success. Gifted and Talented International, 23(2), 119-127.

Kaufman, J. C. \& Sternberg, R. J. (2006). The international handbook of creativity. New York: Cambridge University Press.

Lubart, T. (2007). Psicologia da criatividade. Porto Alegre: Artmed.

MacLaren, I. (2012). The contradictions of policy and practice: creativity in higher education. London Review of Education, 10, 159-172. 
Mariani, M. F. M. \& Alencar, E. M. (2005). Criatividade no trabalho docente segundo professores de História: limites e possibilidades. Psicologia Escolar e Educacional, 9(1), 27-35.

Monteiro, A. S. (2009). Representaçôes de criatividade: um estudo de diferenças na população docente dos ensinos básico e secundário. (Dissertação de Mestrado), Universidade do Minho, Braga.

Morais, M. F. (2013). Creativity: challenges to a key-concept for the 21th century. In A. Antonietti, B. Colombo \& D. Memmert (Eds.), Psychology of creativity: advances in theory, research and application. (pp. 3- 19). New York: Nova.

Morais, M. F. \& Azevedo, I. (2008). Criatividade em contexto escolar: representações de professores dos ensinos básico e secundário. In M. F. Morais \& S. Bahia (Eds.), Criatividade: conceitos, necessidades e intervenção. (pp. 157196). Braga: Psiquilíbrios.

Moscovici, S. (2003). Representaçôes sociais: investigaçôes em psicologia social. Petrópolis: Vozes

Park, S., Lee, S., Oliver, J. S. \& Cramond, B. (2006). Changes in Korean science teachers' perceptions of creativity and science teaching after participating in an overseas professional development program. Journal of Science Teacher Education, 17(1), 37-64.

Romo, M. (2012). Educational creativity: selected research. In Fundacíon Botín (Ed.), Good morning creativity: awakening human potential through education. (pp. 69-86). Santander: Belinda Hayes.

Romo, M. \& Alfonso, V. (2003). Implicit theories of Spanish painters. Creativity Research Journal, 15(4), 409-415.

Runco, M. A. \& Albert, R. S. (2005). Parents' personality and the creative potential of exceptionally gifted boys. Creativity Research Journal, 17(4), 357373.

Runco, M. A., Johnson, D. J. \& Baer, P. K. (1993). Parent's and teachers' implicit theories of children's creativity. Child Study Journal, 23(2), 91-113.

Sanchez, M. P., Martínez, O. L. \& García, C. F. (2003). La creatividad en el contexto escolar: estrategias para favorecerla. Madrid: Pirámide. 
Sarsani, M. R. (1989). The development of reasoning and creativity among the ninth standard students. (Tese de doutorado não publicada), Annamalai University, Tamil Nadu.

Shaheen, R. (2010). Creativity and education. Creative Education, 1(3), 166-169. Recuperado a partir de https://file.scirp.org/pdf/CE20100300004_79654079. pdf.

Starko, A. J. (2010). Creativity in the classroom: schools of curious delight. New York: Routlege.

Sternberg, R. J. (2003). Creative thinking in the classroom. Scandinavian Journal of Educational Research, 47(3), 325-338.

Sternberg, R. J. \& Lubart, T. I. (1995). Defying the crowd cultivating creativity in a culture of conformity. New York: The Free Press.

Tasaduq, N. \& Azim, H. (2012). Creativity levels between private and government school children in Srinager city $\left(7^{\text {th }}-10^{\text {th }}\right.$ grade). Kamla-Raj, 4(3), 255-25. 